Richard H.W. Bradshaw and John Boyle

Department of Geography, University of Liverpool, UK; rhwb@liverpool.ac.uk

Global and regional reconstructions of Holocene vegetation, fire and land-use are essential for understanding the interactions between climate, terrestrial ecosystems, and human activities. Paleoecological approaches based on sub-fossil pollen, macrofossils and charcoal preserved in sedimentary basins are being increasingly integrated with dynamic modeling efforts, a combination that aids both understanding and global synthesis, but poses challenges of effective upscaling of data, downscaling of models, and appropriate data-model comparisons. For vegetation cover and fire incidence this amalgamation is relatively advanced; but integration of historical and archeological information into global ecological models is at an early stage of development. Equally, extending global ecosystem models to consider the biogeochemical consequences of land cover change is very new.

Approaches to vegetation reconstruction have now developed beyond traditional site-based studies into regional mapping based on statistically sophisticated combinations of data. Maps of Holocene vegetation types derived from quantitatively classified pollen data have been compiled for Europe, having developed from single taxon isopoll maps. Modeling of paleovegetation, with the aim of understanding the dominant drivers of vegetation change, began at the global scale and the research challenge has been to upscale site-based pollen data to match the spatial coverage of model output. The BIOME 6000 project developed a successful approach to paleovegetation data-model comparison. Global-scale vegetation biomes were modeled and the site-based pollen data were upscaled to validate the model by biomisation. This was a collective effort amongst pollen analysts, where pollen types were re-classified into plant functional types and then biomes. Data coverage was strongly biased towards regions with long sedimentary records, but this upscaling exercise was of sufficient taxonomic resolution to validate BIOME model output. Biomisation of pollen data is a crude but effective way of standardizing pollen data among sites, but its rigid, prescribed categories, do not fully exploit the numerical or taxonomic complexity of pollen data and are rarely sensitive enough to detect human impact. Subse-

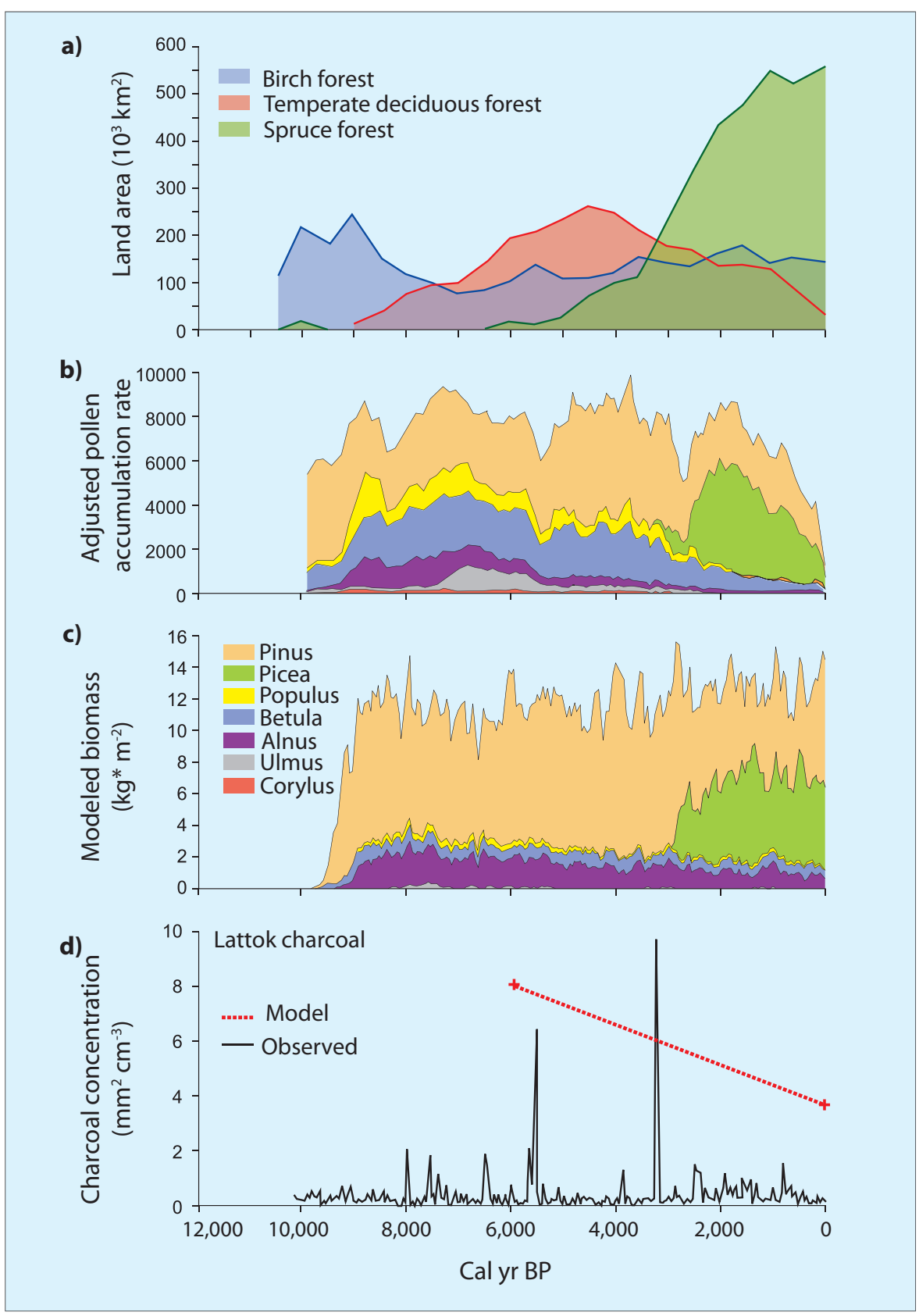

Figure 1: a) Changing forest cover for entire lowland Fennoscandia; $\boldsymbol{b})$ Pollen accumulation rates from a single lake in central Sweden adjusted to reflect abundance of source trees in lake catchment; c) modeled biomass using LPJ-GUESS for the same catchment as b; d) charcoal values from a single lake in northern Sweden (Carcaillet et al., 2007). The broken line joins two modeled estimates of fire return intervals.

quent projects have handled pollen data in other ways to generate regional syntheses of higher spatial resolution.

Odgaard and Rasmussen (2000) combined pollen data from 10 sites in Denmark and using chord distances between prehistoric and recent samples showed that human activities became the dominant driver of vegetation change by $3 \mathrm{kyr}$ $\mathrm{BP}$ in the Late Bronze Age. The POLLAND$C A L$ project took up the challenge of reconstructing forest clearance, as the traditional use of ratios of tree pollen: non-tree pollen was prone to error, due to the nonlinear relationship between open ground and non-tree pollen. The project modeled pollen production and dispersal based on the classical Prentice-Sugita model (Prentice, 1985). The exciting possibility of reconstructing human modification of vegetation over large regions is within reach for the first time by modeling changes in forest cover based on the input of pollen loadings from sites of different size within a region (Sugita, 2007). 
Holmqvist and Bradshaw (unpubl.) give an indication of the scale of dynamic vegetation reconstruction that is feasible by combining tree pollen data from 308 sites in Fennoscandia (excluding mountainous Norway) using neural networks. Six forest types were identified during the Holocene and changes in the areal extent of these types can be mapped by interpolating between the point samples in the relatively flat terrain (Fig. 1a). The temperate deciduous forest type increased its importance about 8.5 kyr BP, reached a maximum about $4.5 \mathrm{kyr}$ BP and then declined in cover up to the present. Data-model comparison at a single location in the boreal forest using the dynamic vegetation model LPJGUESS driven by GCM output also shows a comparable dynamic with peak values for deciduous trees between 5 and $8 \mathrm{kyr}$ BP (Fig.1b, c) (Miller et al., in prep). Pollen data can now be upscaled to cover sub-continents while dynamic model output is at single site resolution. Better matching of scales will help distinguish human-driven vegetation change from that of climate alone.

The IGBP Fast Track Initiative on fire uses data-model comparison to assess the role of climatic change on changing fire frequencies during the Late Quaternary. Fewer charcoal data are available than pollen, and while production and dispersal modeling is in its infancy, progress will likely be more rapid building on the experience of vegetation studies. Carcaillet et al. (2002) suggested that intriguing spatio-temporal patterns in charcoal data do exist. A typical site in northern Sweden records frequent burning between 8 and $6 \mathrm{kyr}$ BP with a second fire-rich period during the last 3,000 years (Fig. 1d). Preliminary modeling suggests decreased fire frequency at present compared with $6 \mathrm{kyr}$ $\mathrm{BP}$ and recent burning may reflect anthropogenic influence.

Modeling the impact of humans on global or regional vegetation requires in-

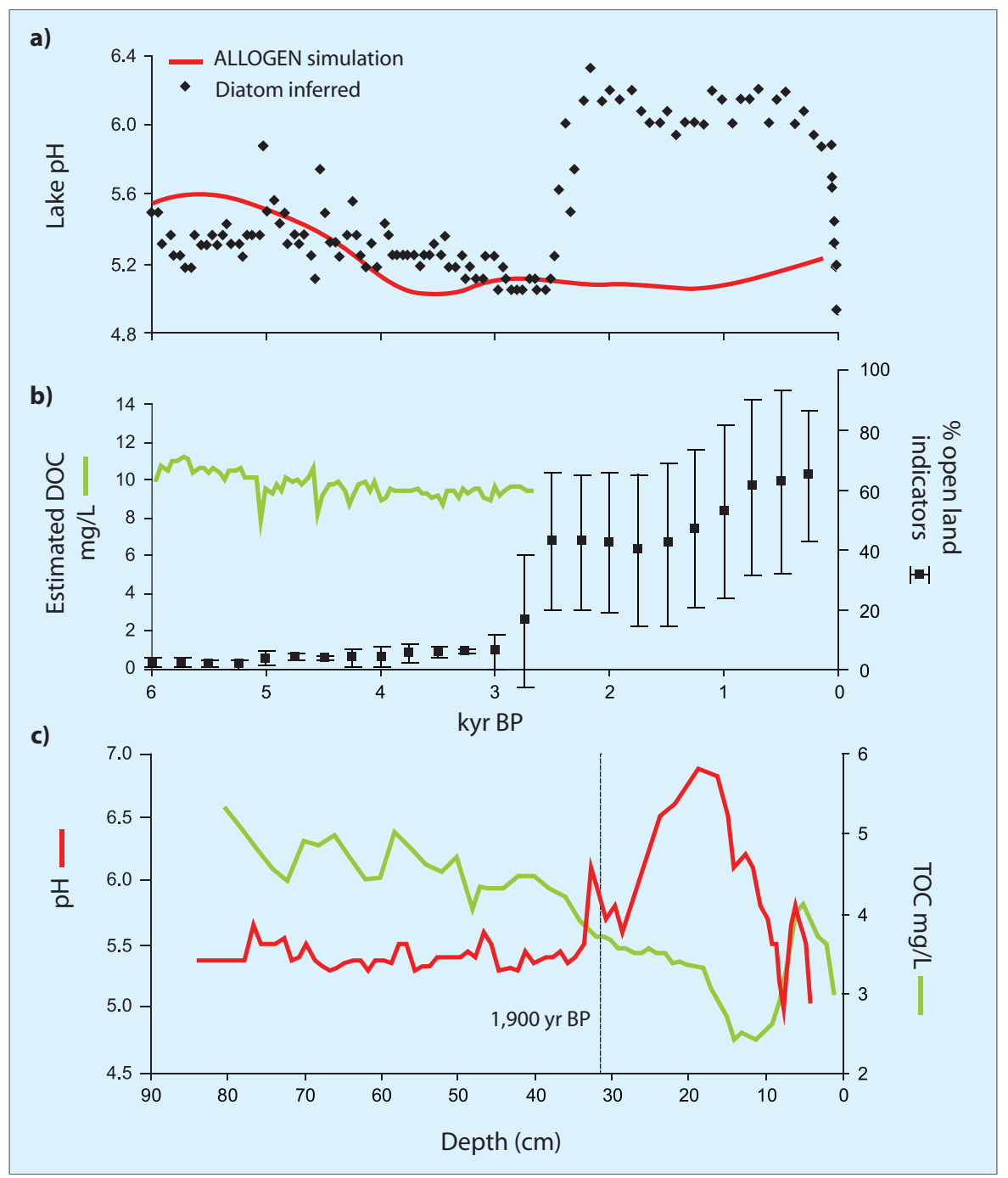

Figure 2: a) Late Holocene lake water pH change at Lilla Öresjön, southern Sweden, diatom inferred (Renberg, 1990) and predicted from climate change and base depletion (simulated by ALLOGEN: Boyle, in press); $\boldsymbol{b}$ ) calculated DOC change required to explain the difference between expected and observed $\mathrm{pH}$, the step coinciding with increased open pollen taxa for southern Sweden (Berglund et al., 1991); c) Diatom inferred pH and Near Infrared Spectroscopy (NIRS) inferred lake water TOC change for nearby Lysevatn (P. Rosén unpubl.).

formation about the extent and intensity of past human activity, and the sensitivity of vegetation to disturbance. Temporal coincidence of changing lake sedimentation regime with pre-historic technological innovation has long been recognized in the British uplands, for example, but realistic modeling requires a far more complete global synthesis of both archeological and paleoecological knowledge. Qualitative archeological syntheses exist in the form of maps of prehistoric land-use, but quantitative modeling is hindered by the difficulty of quantifying either extent or intensity of land-use inferred from archeological data. A promising approach is demonstrated by Olofsson and Hickler (in prep.) whereby a set of generalized rules has been used to translate archeological map evidence, combined with additional physical environment information, into gridded maps of land-use change. These maps are then used to drive the LPJ dynamic vegetation model (Smith et al., 2001) in order to predict the expected impact of prehistoric population growth and technological innovation.

The resulting global model permits quantitative evaluation of archeological and ecological knowledge via inter-comparison of model output with paleoecological data, both using individual sites and regional syntheses. This approach can readily be expanded beyond assessment of early agriculture to include other non-agricultural impacts - such as Mesolithic forest and game management by fire, paving the way to a complete assessment of the impact of early humans on the terrestrial carbon cycle. Validation of such models using paleoecological data is both essential and challenging. For example, a growing body of evidence from China (Zhou Liping, pers. comm.) shows a clear mismatch between archeological evidence for the introduction of new agricultural practices, and paleoecological evidence for significant vegetation change, suggesting that the two approaches must be integrated if we are to reconstruct regional impacts.

Finally, the question arises as to whether the reconstructions of vegetation, fire, and land-use described above can be used to infer changes through the Holocene in the biogeochemical properties of terrestrial ecosystems, specifically carbon budgets and fluxes. Are we in a position to critically examine, for example, the Ruddiman Hypothesis using existing paleoecological data? The simple answer is no; the paleoecological approaches are in their infancy, and geographical coverage of vegetation and land-use reconstruction 
is too patchy. Extending this coverage is straightforward in principle, but paleoecological approaches are more difficult to interpret. Lake sediment records and comparison of such records with geomorphological data indicate landscape destabilization, but provide no direct information about carbon cycling. Organic matter concentration records provide some information, but owing to physical sorting during transport, lake sediments are not an unbiased sample of catchment soils. On the other hand, dissolved organic carbon (DOC) is less subject to alteration during transport and should reflect catchment carbon dynamics. For example, Iron Age agriculture in southern Sweden strongly impacted the diatom-inferred lake $\mathrm{pH}$, causing it to deviate substantially from its expected trajectory driven by base depletion and climate change (Fig. 2a, expected pattern simulated using ALLOGEN, Boyle, in press). This $\mathrm{pH}$ discrepancy implies a halving of the DOC concentration in response to land-use change (Fig. 2b), an interpretation supported by (Fig. 2C, P. Rosén, unpubl.) the newly developed infrared reflectance methods for inferring lake water DOC (Rosén and Persson, 2006). Direct paleoecological reconstruction of past DOC concentration is pivotal to assessing the possible global significance of such land-use change. Diatom inferred DOC records have long existed, but with as many critics as supporters independent methods are essential. Rosén and Persson
(2006) may supply an appropriate method that provides constraints for the biogeochemical significance of Holocene vegetation, fire and land-use changes.

\section{References}

Boyle, J.F., 2007: Loss of apatite caused irreversible early Holocene lake acidification, The Holocene, in press.

Carcaillet, C., et al., 2002: Holocene biomass burning and global dynamics of the carbon cycle, Chemosphere, 49: 845-863.

Odgaard, B.V. and Rasmussen, P., 2000: Origin and temporal development of macro-scale vegetation patterns in the cultural landscape of Denmark, Journal of Ecology, 88: 733-748.

Prentice, I.C., 1985: Pollen Representation, Source Area, and Basin Size toward a Unified Theory of Pollen Analysis, Quaternary Research, 23: 76-86.

Smith, B., Prentice, I.C. and Sykes, M.T., 2001: Representation of vegetation dynamics in the modeling of terrestrial ecosystems: comparing two contrasting approaches within European climate space, Global Ecology and Biogeography, 10: 621-637.

For full references please consult:

www.pages-igbp.org/products/newsletters/ref2007_1.html

\title{
The challenge of reconstructing human impact on large river systems
}

\author{
Thomas Hoffmann ${ }^{1}$, A. LANG ${ }^{2}$ and R. Dikau ${ }^{1}$ \\ 'Department of Geography, University of Bonn, Germany; thomas.hoffmann@uni-bonn.de \\ ²Department of Geography, University of Liverpool, UK
}

In fluvial systems, flooding as well as the associated erosion, transport and deposition of sediments are controlled by climate impacts and moderated by land use. Even though land use and climate are not independent, they change at different spatial and temporal scales, exerting a complex driver pattern on fluvial systems. With respect to the PAGES Focus 4 (PHAROS), which addresses the long-term interactions between past climate, human activities, and other ecological processes, it is of great importance to understand the spatial and temporal dynamics of erosion and sedimentation in more detail. In hydrological and geomorphological terms, the data are proxies for long-term changes in flood regime; the long-term erosion of soil, sediment and organic matter; and the changing sediment flux to coastal systems. From an ecological point of view, the importance lies in terms of understanding nutrient delivery downstream (to the coastal zone) and in modifying channel and riparian habitats. River systems are characterized by intricate behavior with variable sediment sources, temporal gaps in downstream sediment propagation and changing trapping efficiency of sediment sinks. The most promising concept for understanding such complexities is the sediment budget approach. If available at a variety of spatial and temporal scales, sediment budgets allow unraveling the dynamic behavior and thus the trajectory of river response. Despite numerous sedi- ment budgets available for small drainage basins and longer time spans (millennia) as well as for large drainage basins and short time spans (decades), little is known about the response of large fluvial systems on temporal scales that match the period of human impact-knowledge that is essential for the integration of river based sediment fluxes in global biogeochemical cycles.

On the time scales of centuries and millennia, rivers cannot be viewed as conveyor belts that just deliver eroded soil and sediment to the oceans. Within-basin storage on slopes and in floodplains is essential and often exceeds delivery (Hoffmann, 2007). Also, the coupling relationships and the efficiency of sediment delivery between system components are dynamic functions that change as a river basin adjusts to external triggers.

A multitude of results from case studies is available for many river catchments. Data for sediment transport and deposition are available from colluvial deposits, lake sediments and floodplain sediments. This data is usually scattered and upscaling for deriving system-wide information is difficult. Presently, databases of dated floodplain units are being built for several river systems (e.g. Macklin et al., 2006) to improve this situation, facilitate system-wide analyses, and establish gaps in knowledge. Information stored includes sedimentary environment, stratigraphy and age. Much of these data are used to reconstruct the frequency of deposited floodplain units, which can be interpreted as a proxy for flood frequency and magnitude. Here we focus on floodplain data as an archive of sediment flux for specific large river catchments. Currently available data is still insufficient for constructing sediment flux but allows extracting age and depth information for individual system components. This can be used for calculating sedimentation rates in a way similar to Shi (2002) and Knox (2006) for the Yellow and Mississippi rivers, respectively. This approach loses temporal resolution as it only allows constructing average rates - the effect of which is shown in the inset of Figure 1c.

The Yellow River (Fig. 1a) shows in general increasing maximum sedimentation rates during the Holocene (Shi, 2002). The general slow increasing trend is superimposed by strongly accelerated sedimentation rates due to human impacts during the last 2,500 years. Based on the assumption that the natural increasing trend (before the human impact) did not change during the last 2,500 years, Shi (2002) calculated a 1.6 fold increase of mean sedimentation rates during the last 2,500 years due to human impacts.

The Yellow River is characterized by a long history of agricultural activities with an overall increasing intensity over several thousand years. In contrast, significant human impact on the Upper Mississippi River is significantly younger. It started only 200

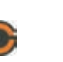

